\title{
Discurso de paraninfo aos bacharelandos de 1952
}

\author{
Gabriel de Rezende Filho \\ (Catedrático de Direito Judiciário Civil)
}

Meus caros paraninfados.

A nímia gentileza do vosso gesto, aclamando-me vosso paraninfo, envolve, com a simpatia de que tais atos se revestem, o prestígio em que quisestes colocar-me e constitui elevada honra, da qual não poderia declinar.

Deverieis, em verdade, ter escolhido para tão agradảvel incumbência outro professor da nossa Faculdade, capaz, pelos seus dotes oratórios e pelo seu saber, de fascinar esta brilhante assembléia, propiciando-lhe um banquete espiritual pela formosura do discurso e profundeza das idéias.

Já que insististes, porẻm, aqui compareço a esta pomposa festa de confraternização - um deslumbramento de Iuzes e de flores - a fim de atender ao vosso apêlo, com o coração esmagado pela vossa bondade.

Que mais significativo prêmio poderia, aliảs, desejar, já no outono da minha vida de professor, do que êste?

Que melhor e mais carinhosa recompensa poderia eu pretender do que essa generosa prova da vossa simpatia e solidariedade?

Sou, ainda, profundamente grato às amáveis palavras do vosso eloquente intérprete ao atribuir-me virtudes e qualidades que não possuo, procuranđo realçar o professor que convosco conviveu durante três longos anos e que há. mais de quatro lustros vem se dedicando na velha e tradi- 
cional Faculdade ao árduo mister ye ensinar aơs moçoș ministrando-lhes os elementos necessários à vida prâticar no desempenho das atividades a que o diploma de bacharel em ciências jurídicas e sociais dá direito.

Esta festa de confraternização è de intensa alegria, de justificado júbilo pelo prêmio que alcanrastes, coroando a vossa carreira, os vossos estudos, a vossa dedicação no curso acadêmico.

È também uma festa de saudade, pois, em essência, significa um adeus, um último encontro de despedida.

Ao ingressardes na seara dos estudos jurídicos, estaveis certamente convictos de que dentro de alguns anos de esfôrço continuado chegaríeis à meta final.

Durante cinco anos de manuseio de livros e apostilas, de salutar convivência com os mestres, conservastes, bem o sei, impávida, a chama do ideal.

Após uma labuta perseverante, vencestes a auspiciosa etapa, que vos habilita a encarar corajosamente o futuro, conduzidos pelos ventos da fé e da esperança.

Transpuzestes os umbrais da velha Escola, deixastes para sempre a vida remançosa das arcadas, aquêle ninho benfazêjo onde se bosquejaram os contornos de vossa formação intelectual, onde o vosso espírito, $\overrightarrow{\text { de }}$ enivolta com os sonhos e as ilusões juvenis, já madrugava, entretanto, para para as penosas cogitações do direito.

Bem avalio os sentimentos de ansieđade a de esperança que vos assaltam o coração nesta hora de vossa dispersão, ao partirdes para novos rumos, ao ganhardes o largo campo em que pròpriamente se iniciarả a vossa vida.

Bem forte deve ser, realmente, a vibração de que vos achais possuídos, quando o vosso primeiro triunfo nas letras jurídicas vos impele para um novo cenário,, para um mundo diferente daquele em que até agora vivestes. 
As minhas palavras nesta festa, palavras descoloridas, despretenciosas, sem os necessários atavios, despidas de grandiloquência, mas sinceras, serão hoje - como sempre o foram na cátedra, durante os anos da nossa convivência dentro da querida Faculdade - palavras amigas, de confôrto, de estímulo, de exaltação, a fim de que possais enfrentar decididamente, com fé e patriotismo, a realidade da vida prática.

A vossa geração, meus jovens colegas, está naturalmente inquieta com o panorama do mundo que todos divisamos.

Tem-se a impressão de que a civilização, tocada até ao cerne de um utilitarismo desenfreado, de um materialismo impressionante, vai imergindo aos poucos num período crepuscular da história, pela dissolução das mais belas tradições moraiş.

Vê-se por tôda a parte o estiolamento dos preceitos da decência, do civismo, da moralidade, da religião, repercưtindo fundo na vida da familia e da sociedade, na política, na administração pública.

Vivemos, indubítàvelmente, uma época agitada, conturbada, trágica, em que se procura, por todos os meios, o equilíbrio dos sistemas políticos, o ajustamento das soluções econômicas, a exatidão das doutrinas filosóficas.

O momento - ninguẻm o negará - é, realmente, de universal inquietação. Os homens de há muito não se compreendem, combatem-se e as ideologias inconailiáveis $\mathrm{e}$ antagônicas do Oriente e do Ocidente afastaram definitivamente uns povos de outros.

Ainda ontem, na sua alocução da Páscoa, pediu Sua Santidade o Papa Pio XII à multidão comprimida na Praça de São Pedro que procurassem todos inspiração na Ressurreição de Cristo para as lutas pelo bem e pela paz, 
afịmando que, infelizmente, o mundo continua nos mortais caminhos do ódio.

Atentando para a realidade, como ela se nos apresenta na maioria dos povos, percebe-se desde logo que as desproporções entre a produção e o consumo, a desvalorização das moedas, o desequilíbrio dos orçamentos, a luta pela conquista dos mercados internacionais, o custo excessivo da vida, que vai subindo assustadoramente, inutilizando quaisquer previsões e trazendo um clima de revolta em tôda a parte - e apenas assinalo algumas das causas desta dolorosa crise mundial - tudo isso está naturalmente criando uma série de problemas, que tanto vêm preocupando economistas, financistas, sociologos e juristas.

Os desajustamentos são evidentes.

Em meio desta confusão, o direito - fator máximo da estabilidade social - tem um papel relevantíssimo.

Os dados econômicos e sociais, revelados pelas transformações operadas pelas invenções e pelas novas idéias políticas e filosóficas, imprimiram ao direito uma feição nova, que é preciso examinar com cuidado.

Diretrizes várias vão nos impelindo para caminhos nunca dantes imaginados.

A evolução jurídica, nestes últimos tempos, tem-se leito muito rápidamente.

Certos principios, considerados como axfomáticos, e que eram a base do direito, foram-se modificando através do impulso de estranhos fatôres.

Incontestảvel a progressão do direito, a despeito da inû́» til revolta de uns tanto conservadores, acastelados na cidade do passado, bem longe das realidades, a proclamarem a imutabilidade dos princípios tradicionais e a profligarem as novas idéias e os legítimos anseios da atualidade, esquecidos de que as fôrças da renovação são sempre indomáveis.

O direito, afinal, não é um repositório de preconceitos, não é uma criação abstrata da mente humana, āntes um 
organismo vivo, refletindo os usos, os costumes, as tendências, as necessidades e as exigências da sociedade.

Não é o produto do simples raciocínio do homem, estático e invariável, mas dinâmíco, desenvolvendo-se e tranformando-se de acôrdo com as necessidades e as condições econômicas, materiais e psicológicas do povo.

Constituirá sempre uma técnica a serviço dos ideais e, por isso, pronto a adaptar-se às realídades da vida.

"O direito é essencialmente variável e protéico, faz-se, desfaz-se, refaz-se incessantemente, num perpétuo estado de vir-a-ser". (Edmond Picard, Le droit pur).

Aí estão os ensinamentos da história para provar que todos os grandes movimentos, que sacudiram a humanidade, dando a impressão de completo desmoronamento dos princípios jurídicos, até então tidos como dogmas inatacáveis, acabaram, afinal, pelo ressurgimento do próprio direito adaptado às novas condições sociais.

E que os velhos principios têm de ceder o passo às reinvindicações que vão surgindo, exigindo profundas alterações.

Basta observar de relance alguns importantes movimentos de outras eras.

Roma, ao tempo da invasão dos bárbaros, não caíu em definitivo, porque, se o Império ruíu, desmantelando-se aquêle poderoso Estado, dono até então do mundo, o direito romano, passados os tempos de confusão, revigorouse, continuou o seu primado, vindo a constituir a fonte das legislações ocidentais.

A Revolução Francêsa, que marca o início da época contemporânea, representou tambẻm para o seu tempo um fecundo movimento de renovação das velhas instituições, elevando o homem da condição inferior em que o mantinha ainda o feudalismo a uma nova categoria social, reconhecendo-lhe direitos invioláveis, anteriores ao Estado, e proporcionando-lhe, no mesmo passo, novos ideais de progresso e civilização. 
Modificou-se, então, o panorama do mundo.

A transformação dos institutos jurídicos operou-se como um fenômeno fatal.

A suprema aspiração, com a queda das classes dominantes, que não queriam reconhecer os direitos do povo, foi a libertação e a dignificação do homem, a igualdade e a fraternidade.

A todos pareceu, então, que a legítima e definitiva conquista da civilização era o individualismo filosófico, sistema de vida que possibilitaria a realização da liberdade na ordem civil e política, considerando a sociedade como um conjunto de sêres livres, dotados de capacidade, discernimento e vontade, com direitos anteriores ao Estado, inseparáveis de sua personalidade.

Nesse regime de liberdade puderam os indivíduos cuidar, com autonomia, de seus interêsses e negócios, amparados pelo direito.

O Estado não constituía senão um organismo superior, necessário para a mantença da ordem jurídica, facilitando a todos a conquista e o uso das riquezas.

A ordem jurídica assentou-se nesses postulados.

Com o predomínio do individualismo jurídico, cresceram e frutificaram as instituições.

Os filósofos viam, então, nesse sistema a única realidade.

O direito - segundo o entendimento geral - tinha por fundamento a liberdade individual.

$O$ indivíduo era o fim da sociedade. $O$ bem individual era a única determinante da vida social.

$O$ indíviduo, em suma, era encarado como um ser abstrato.

Daí, a prevalência do princípio da autonomia da vontade individual com o lógico consectário do respeito a essa mesma liberdade.

A consequência dessa orientação, no entanto, sỏ podia levar à absorção do fraco pelo forte e ao aniquilamentos 
da própria liberdade individual, que acabou sendo destruída pelos fatos.

Os tempos, porém, mudaram.

Estamos no limiar de uma nova era.

Pertence já a um passado remoto a época do romantismo político e do liberalismo econômico.

O cenário, que hoje contemplamos, é bem diverso daquele que parecia definitivo no século 19 .

Com a concepção social, que se vai impondo de modo irredutível, o individualismo, pode-se dizer, vê encerrado. o seu ciclo histórico.

Vai por tôda a parte uma febre de reformas, uma série de realizações em todos os campos da atividade humana, em tôdas as esferas da vida.

o direito, de individualista que era, torna-se direito de cooperação, direito de interdependência entre o indivíduo e a sociedade.

Já a seu tempo, dizia Rur Barbosa (A questão social e política no Brasil) que "a concepção individualista dos direitos humanos tem evoluído ràpidamente, com os tremendos sucessos dêste século, para uma transformação incomensurável nas noções jurídicas do individualismo restrin-gidas agora pór uma extensão, cada vez maior, dos direitos. sociais. Já se não vê na sociedade um mero agregado,. uma justaposição de unidades individuais, acastelado cada qual no seu direito intratável, mas uma entidade na-turalmente organizada, em que a esfera do indivíduo tem por limites inevitáveis, de todos os lados, a coletividade. 0 direito vai cedendo à moral, o indivíduo à associação, o egoísmo à solidariedade humana."

"Direito humanitário -- acentuava também EDMond Pigard - como tem sido denominado, colimando a harmonia dos elementos componentes da sociedade, visando uma justiça que abrace a sociedade inteira, não dê vantagens: apenas a uns, mas a todos, e sobretudo aos mais fracos, 
aos necessitados de amparo, não esquecendo ninguém, penetrando o organismo social como um fluido benéfico."

Ordem jurídica nova, em suma.

Qual, porém, o sentido dessa evolução juridica?

Se o direito é o produto de determinada cultura, acompanhará fatalmente o estilo da vida moderna.

O século 19 foi o grande século, quando a humanidade progrediu assombrosamente, realizando grandes coisas no domínio do pensamento e da ação.

O século 20, porém, nasceu no sangue e as duas grandes guerras que surgiram com pequeno intervalo destruiram principalmente a fé nos princípios que até então vigoravam sem discussão.

Quem ousará profetizar o que vai acontecer?

Quem tentará penetrar nas regiões ignotas do futuro?

Interrogações que dominam qualquer pessoa, interrogações que cada um de nós a si próprio se formula, com a alma apreensiva.

Que importa a grandiosidade das obras materiais, dêsses inventos geniais, dêsses esforços incríveis no campo da matéria?

Sente-se que há uma crise geral e, por isso, não é de espantar se chegue a falar em crise do direito, em decadência do direito e até mesmo em negação do direito.

As principais causas da atual crise do direito, observa Georges Rippert (o declínio do direito), devem ser procuradas na intervenção cada vez maior do Estado na ordem privada, na tendência que se vai generalizando em transformar boa parte do direito privado em direito público, no enfraquecimento dos direitos individuais.

$\mathrm{E}$, acrescenta o mestre francês, em consequência de tudo isso, surge o clima de insegurança jurídica e o espírito de desobediência.

É fatal, então, êsse ceticismo jurídico, com filósofos a descrerem do direito natural e juristas, seguidores do marxismo, a sustentarem que o direito e o Estado nada mais 
são do que o reflexo ou a projeção dos fatos econômicos, elementos da superestrutura debaixo da qual se esconde a realidade econômica; a negarem a existência de direitos individuais anteriores ao Estado, afirmando que o direito do Estado é sempre superior a qualquer direito individual.

Tudo isso é deveras alarmante, porque assim periclita a sorte do direito.

Estejamos certos, porém, de que, na realidade, o direito ainda permanece como a principal fôrça social.

Como concebermos uma sociedade sem normas de procedimento, ditadas pelo Estado?

O direito há de ser sempre a fôrça garantidora da estabilidade social. Ubi societas, ibi jus.

Em sua essência, o direito deve ser considerado como algo superior às contingências do tempo, independente de época ou de ordem social determinada.

Incontestável é a tendência atual da doutrina e da legislação para a democratização do direito, fazendo com que êle possa corresponder ao anseios dos novos tempos, moderando os poderosos, refreiando-lhes os abuisos, amparando os desprotegidos e humildes, evitando as desigualdades sociais, que acarretam as revoltas e trazem o clima propício para as reivindicações pela fôrça.

Meio de defesa contra o excesso do capitalismo, preocupação com a justiça social, valorização cada vez maior do trabalho e respeito pela personalidade humana - eis os marcantes aspectos da evolução jurídica atual.

No campo do direito privado - focalizaremos, ràpidamente, apenas alguns de seus institutos - vemos quanto têm feito ùltimamente os juristas, empenhados em amoldar os princípios de fundo social do direito às realidades da vida. 
Ao princípio de liberdade, que é fundamento dos direitos subjetivos, conjugam o principio de solidariedade, e, assim, orientadas pelo clarão da moral, têm surgido algumas concepções humanitárias, assegurando aos homens os bens da vida e obstando quanto possível ao surto e vitória dos instintos brutais e egoísticos.

Nas relações contratuais, a autonomia da vontade não. é mais o tabu dos velhos tempos e, consequentemente, a obrigação de cumprir os ajustes condiciona-se, antes de tudo, aos seus reflexos na consciência coletiva.

É a chamada teoria da imprevisão, conquista do direito moderno, segundo a qual a intangibilidade dos contratos, antes considerados como lei entre as partes, não é mais um princípio rígido, pois, pela aplicação da regra rebus sic stantibus, que se vai insinuando na legislação e na jurisprudência, torna-se possivel a atenuação e mesmo. o rompimento das convenções, quando seja certo que na sua execução, dada a radical e inesperada mutação das condições de fato, um dos contraentes pode arrastar o outro à ruína e ao desespêro.

Se acontecimentos excepcionais e imprevistos ao tempo da conclusão dos contratos opõem-se a que as partes possam cumprí-los, dado o seu prejuízo infalível, é de admitir-se que a justiça, considerando com equanimidade a situação dos contratantes, modifique o cumprimento da obrigação, prorrogando-lhe o têrmo ou reduzindo-lhe a importância.

Quanto à responsabilidade extra-contratual, a tendência moderna é para substituir o criterrio subjetivo pelo objetivo, dada a ineficácia do primeiro, gerador em muitos casos de profundas injustiças. Deixou de fundar-se sempre na culpa e vai cedendo o passo à teoria do risco.

$\mathrm{E}$ aí estão, tambẻm, as vitoriosas doutrinas do abuso. do direito e do enriquecimento ilícito, tocadas de luminoso sentido de humanidade, constituindo-se em poderosos meios de democratização do direito. 
No campo do direito das coisas, a propriedade, cuja garantia está expressamente estabelecida na Constituição, sujeita-se, ainda assim, segundo o próprio texto legal, a muitas restrições, condicionada como se acha ao bem estar coletivo.

Quão longe estamos hoje do conceito de domínio, herdado do direito romano e do antigo direito português!

À sua feição de direito absoluto, opõe-se a teoria da propriedade como função social.

A propriedade, segundo LÉon Dugurt, nâo é mais o direito subjetivo do proprietário, e sim a função social do detentor da riqueza.

Leis existem restringindo o dominio absoluto, bastando lembrar as relativas às quedas d'água, à exploração do subsolo e das florestas, e as respeitantes ao direito de construir e ao direito de arrendar imóveis urbanos.

Não escapou a essa tendência renovadora o próprio direito de família, embora nesse campo as modificações só se possam fazer com prudência e progressivamente.

O fator econômico vai exigindo a emancipação gradual da mulher, havendo juristas que preconizam o estabelecimento de perfeita igualdade entre ela e o homem.

As relações de família são encaradas não sob o prisma de estreito individualismo, mas dentro de um ângulo visual mais humano, inspirado nas tendências sociais modernas.

$O$ pátrio poder sofrea a influência da promulgação do Código de Menores, onde se disciplinam os casos de suspensão e de perda do mesmo poder, com medidas de proteção aos que ainda não completaram 18 anos.

Consagra, ainda, a Constituição um capítulo à familia, declarando-a sob a proteção especial do Estado.

Inspirada nos princípios de justiça social, a lei n. 883, de 21 de outubro de 1949, revogando o dec. lei n. 4737, de 1942, que só permitia o reconhecimento dos filhos adulterinos após o desquite, faculta, de um modo muito mais amplo, êsse reconhecimento a qualquer dos cônjuges após 
a dissolução do casamento e concede ao filho ação para que sua filiação seja declarada.

Concretizou essa lei a aspiração de Clovis Beviláqua, que proclamava a necessidade de eliminar do nosso direito quaisquer diferenças entre os vários tipos de filiação, reconhecendo-se a todos igualmente o direito de viver.

E que dizer da legislação trabalhista, com seus princípios humanitários, que a Igreja Católica de há muito preconizava, quando não haviam sido ainda objeto de cogitação nas legislações dos povos cultos?

Com efeito, a aura balsâmica de solidariedade humana vem soprando desde a famosa enciclica Rerum Novarum do Papa Leão XIII, confirmada e desenvolvida pela não menos célebre enciclica Quadragesimo Ano do Papa Pio X.

$\mathrm{O}$ direito do trabalho, que ultrapassou o campo do direito civil para constituir um ramo autônomo, é, sem dúvida, uma demonstração eloquente, concreta, objetiva da vitória do espírito social, que domina atualmente todos os ramos do Direito.

Insurgindo-se contra o rigorismo dos preceitos do direito comum, limitando o gôzo de certas prerrogativas individuais, as leis trabalhistas revelam a evolução do direito brasileiro nestes últimos tempos. Constitui, sem dúvida, o direito do trabalho o aspecto mais interessante e sugestivo de transformação do direito, pois é aquele em que melhor se percebe a relatividade das regras e instituições jurídicas.

Aflorados êstes problemas jurídicos -- com o que visei. dempertar a vossa atenção e estimular os vossos estudos podemos concluir, meus caros paraninfados, que nãc existe: absolutamente decadência do direito. 
A chamada crise do direito nada mais é do que uma crise de transição, um reajustamento forçado da consciência jurídica das classes que estruturam o mundo hodierno.

Bem sei que a evolução do direito, que se processa de um modo rápido e por vêzes desconcertante, constitui, sob. vários aspectos, uma verdadeira incógnita, mas a verdade é que, afastando pessimismos e maus augúrios, devernos nos bater para que a humanidade não se descarte dos principios eternos do direito e da justiça, embora possam ser traduzidos em fórmula mais adequada e própria a remediar os males que nos afligem.

"Por fôrça das necessidades novas - diz o Professor Vicente RÁo ( $O$ direito e a vida dos direitos) - novas regras são necessárias para a solução dos problemas do nosso tempo. Transforma-se, pois, o direito, no sentido de maior extensão de seu poder normativo, mas semelhante extensão não destrói, antes confirma, dia a dia, a generalidade e a universalidade dos princípios gerais".

Cumpre-nos, assim, ciosos do passado, mas preocupados com o futuro, zelar pelo magnifico corpo de doutrina que nos legaram nossos maiores, afeiçoando-o apenas às necessidades dos tempos atuais.

Os tempos modernos, por outro lado, estão a exigir a mobilização de todos os homens a fim de empenharem seus melhores esforços contra as fôrças do mal, baseadas no egoísmo e no materialismo.

A civilização, êsse espantoso apogeu da tẻcnica, não é apenas o produto das atividades materiais, por mais florescentes que sejam, mas também da fôrça do espírito, graças à qual foi possivel o aperfeiçoamento das ciências e das artes.

Lutemos, pois, pela cultura, porque estaremos lutando pela liberdade e pelo fortalecimento das bases espirituais: 
da nação, e, especialmente, da cultura jurídica, que é uma tradição viva e imarcessível da nossa centenária e gloriosa Faculdade.

Apóstolos do direito, solidifiquemos no nosso espírito a confiança no seu primado, na sua supremacia, pois 0 direito é a fôrça iniludível de todos os destinos humanos. é a condição da vida organizada da sociedade.

Tenhamos fé, pois onde ela não existe tudo se estagıı e morre.

Com o perecimento do direito, surgìria a decadência fatal da humanidade.

Deus nos livre de semelhante vaticinio ou de uma tal desesperança! Sursum corda.

Lembremos estas palavras de Rur: "O Cristo disse que o homem não vive só de pão. Sim, porque vive de pão e do ideal. O pão é o ventre, centro da vida orgânica. $O$ ideal é o espírito, órgão da vida eterna. Entendei como quiserdes a eternidade e a espiritualidade. Se debaixo de de uma ou de outra forma - que será o ideal mais ou menos celeste, mais ou menos terrestre - não as admitirdes, tereis reduzido os entes racionais à animalidade."

Meus jovens colegas.

Escolhestes a mais bela e uma das mais nobres e dignificantes das profissões liberais.

O campo em que ides agir é bem vasto, reclamando ingente e penoso esfôrço e constante dedicação.

Abraçastes um verdadeiro sacerdócio, que não vos há de propiciar, por certo, vida tranquila.

Os problemas juridicos, como salientei, nuca foram tão graves e complexos, e tereis, por isso, como juristas, grande responsabilidade.

Qualquer que seja a direção que tomardes na vida prảtica, no desempenho de atividade que julgardes mais conveniente e conforme aos vossos desejos, seja na elaboração ou na aplicação das leis, seja na administração pública, 
ou na política, seja no exercicio da advocacia, ou, ainda, no ensino do direito, entregai-vos confiantes à tarefa de cada dia, honrando o título que alcançastes.

Com a vossa inteligência e cultura, ponde sempre na conquista do vosso ideal todo o poder maravilhoso do vosso entusiasmo de moços.

Conscientes da responsabilidade que assumistes, contribuìreis, certamente, pela palavra e pela ação, para a vitória dos princípios do direito e da liberdade, fiéis ao lema do vosso quadro de formatura - Pro Jure Et Libertate Pugnabimus!

Na guarda e na defesa dos princípios da justiça, no cumprimento sereno e rigoroso dos vossos deveres, havereis de conquistar o mais belo triunfo e o mais consolador dos prêmios.

Só assim estareis honrando a nossa amorável Faculdade, que é a Casa viva, a Casa eterna, guarda vigilante e incorruptível das nossas tradições liberais, que se mantém altaneira através das geraçōes que por ela têm passado, que desafia os tempos e os homens. Casa, como disse esplêndidamente Rui, "em que debaixo de seus tectos, duas evidências há que nos consolam, nos desmaginam e chegam a desconvencer-nos da morte: a continuidade da tradição e a continuidade da justiça". 